\title{
Research on Combination of Intangible Cultural Heritage and Augmented Reality
}

\author{
Tao Yang \\ Dalian Neusoft University of Information \\ Dalian, China
}

\author{
Ran Zhao \\ Dalian Neusoft University of Information \\ Dalian, China
}

\begin{abstract}
Nowadays, countries around the world put the digital protection of intangible cultural heritage on the agenda. It is the innovation integration of cultural transmission and digital technology. The development of communication technology, 3D technology and digital technology promotes the effective integration of augmented reality technology and intangible cultural heritage. This paper analyzes the protection status of intangible cultural heritage and the possibility of combining the two through cases, contributing to the transmission and inheritance of Chinese culture theoretically.
\end{abstract}

Keywords-intangible cultural heritage; augmented realit; innovation integration

\section{INTRODUCTION}

According to the "improvement of national cultural soft power through cultural innovation" proposed in the 12th five-year plan from 2011 to 2015 , it requires us to stick to traditional national culture and encourages pioneer thinking innovation and entrepreneurial practice. It proposes in some opinions on promoting the development of cultural industries in China issued by General Office of the State Council that the supplement of intangible cultural heritage and digitalized products forms through policy promotion. Driven by scientific and technological progress, the inheritance and protection of intangible cultural heritage gradually forms the development trend of "point, line and plane", and has achieved teaching results with promotion value and significance in theory, technology, culture and practice.

\section{CURRENT SITUATION OF TRANSMISSION AND}

INHERITANCE OF INTANGIBLE CULTURAL HERITAGE

In the 21 st century dominated by culture, with the economic development, countries realize the importance of cultural transmission that has economic, political and national influence. Intangible cultural heritage plays an important role in cultural transmission. The intangible cultural heritage in China has abundant species, huge quantity, long history and wide transmission as well as manifests national characteristics. In July 16, 2014, the State Council issued the fourth batch of national intangible cultural heritage list, including 153 intangible cultural heritages of folk literature, traditional music, traditional dance, traditional drama, Chinese folk art forms, traditional sports, entertainment and acrobatics, traditional fine arts, traditional skills, traditional medicine and folk custom. In 2016, our country established the fifth batch of intangible cultural heritage list $\mathrm{i}$, making unprecedented efforts to protect folk culture. With the change of contents of digital art education, the two combine and promote each other. The integration of culture and technology will inevitably become the powerful means to inherit and spread folk culture and achieve effective results. "Suggestions" in the national "13th fiveyear" plan clearly propose: promote the integrative development of traditional media and new media, accelerate the digitalization construction and develop new type transboundary media and promote the cultural development and prosperity. Furthermore, promote cultural innovation and inheritance and spread Chinese culture through "the Belt and Road", in order to improve national cultural soft power.

\section{DeVElopment Status of AugMented REAlity TECHNOLOGY}

Augmented Reality (hereinafter referred to as AR) technology combines 3D model, 3D image and text information with the real world and shows more external information, integrating vision, sound sensation, touch, gustatory sensation and smell. The improvement of technology depends on the continuous development of science and technology. However, the seamless integration of vision and auditory sense has mature development. Virtual elements and real elements are integrated into new information system perceived by human brain through visual input. Real environment and virtual information are integrated in the same picture or space in real time, so that we have the surreal sense experience. The core theoretical framework of $\mathrm{AR}$ is to integrate science and technology, information, culture, recreation and digital forms in real material and cultural products. AR technology displays contents and provides interaction with entities. Therefore, we can exploit the excellent advantages of this technology to the full in exhibition, transmission and inheritance of intangible cultural heritage. Specifically, we can express cultural contents through digitalization, introduce the history and process of intangible cultural heritage through exhibition and digital animation and display its design and production process, representative handiworks and types of cultural and creative products as well as cultural landscape through animation. The integration of intangible cultural heritage and AR technology opens a new path in technology and transmission routes. Meanwhile, it can combine with the 
development of culture creativity, tourism, animation design and $3 \mathrm{D}$ production.

AR technology adopts new type man-machine interface and simulation tools, attracting more attentions of scientific and technological corporations and investors throughout the world. It has achieved results in culture creativity, games and exhibition. With the increasing improvement of functions of communication equipment and the coming of communication technology and $4 \mathrm{G}$ and $5 \mathrm{G}$, AR technology is known and enjoyed by the public and brings revolutionary changes in graphic simulation, artificial intelligence, recreation, CAD design, virtual communication, fax remote sensing and military simulation training. During the Spring Festival Gala in 2017, Alipay subordinate to Alibaba uses AR technology to send red packet, letting users visually experience the AR technology. AR technology is changing our world and bringing many benefits.

At present, few companies in our country devote to AR technology. Except for several big internet companies that try it beyond the existing business (such as "Checker"), few companies truly own and develop mobile AR technology. Our country should devote to the development of AR technology. In our country, AR is still at the initial stage. Enterprises in this field have concentrated on the research and development as well as application of "AR", such as ARTable formed by OPEN-VRP AR engine, perceptual recognition module, AR module and interactive experience system, showing the interaction between exhibits and viewers and effects of related information. ii The Hannover Messe held in Germany every year attracts countless scientific and technological corporations and investors who aim at AR technology. In 2016, Magic Leap Company got the investment of many renowned giant companies. The short film of "new morning" with duration of four minutes issued by it in April 2016 did not use any special effect and synthetic technology. It combines entity landscape with virtual effect and achieves breathtaking effects. Meanwhile, it acquires the assessment value of nearly six to eight billion U.S. dollars after D round of financing.

Digital protection is the mainstream direction of intangible cultural heritage protection. iii The integration of intangible cultural heritage and digital media technology is the foundation in application of AR technology. Intangible cultural heritage is a cultural form. Multimedia technology combines vision, sound, character, animation even gustatory sensation, enriching artistic dissemination and expression forms and improving the artistic appeal and historical sense of intangible cultural heritage. On technology level, AR technology is more advanced man-machine interaction. It simulates the functions of people's sense organs and makes people absorbed in the virtual world generated by algorithm that they can see, listen, touch and smell. People can achieve real-time interaction through language, gestures, body movement and movement of sight line. It may be called "there is something of each in the other". In the interaction, it can reconstruct the historic building and ancient relics in intangible cultural heritage as well as show the formation of these contents, letting people have the experience that they cannot feel in the real world. The development status of digital art has provided foundation of art and technology for integration of AR technology.

\section{INTEGRATION AND INNOVATION OF INTANGIBLE CUltural Heritage AND AR TECHNOlOGY}

The integration and innovation of intangible cultural heritage and AR technology carries out visual, virtual, realtime and interactive expression of cultural contents through digital forms. The continuous development of AR technology provides new media for the transmission of intangible cultural heritage and is regarded as an innovative practice.

\section{A. Integration and Innovation of Interactive Media Application (Mobile Phone APP) and AR Technology}

AR technology will exploit the advantages of interaction and interestingness to the full in the field of intangible culture. The influences of AR technology on education include knowledge visualization, real-time interaction and surreal sensory experience. The research in this project is to let AR technology promote knowledge transfer through the learning environment of virtuality and reality combination and carry out teaching through lively activities. With the combination of mobile devices and AR technology, mobile learning and independent learning come true. AR technology and mobile platform can vividly show 3D contents corresponding to $2 \mathrm{D}$ contents in paper books with landscape display and illustration.

\section{B. Integration and Innovation of Cultural Center, Museum and AR Technology}

Most exhibits in museums are tangible historical relics. Exhibits related to intangible cultural heritage are scanty and have backward forms. iv Interaction technique related to AR has appeared. Like the video of sixth sense technology, we can do many unimaginable things through configuring micro objects with electronic induction on exhibits, such as use hands to simulate shooting, dial virtual phone, take out card to play King of Glory and racing parade. The information is projected onto a plane. In the near future, we can touch the information emerging before our eyes and manipulate pictures through distance sense devices. The Google Goggle issued by Google and HoloLens issued by Microsoft make people pay high attention to AR technology. AR applications similar to Google Goggle spring up. For example, when you see an exhibition on ancient relics, you can scan the entity before your eyes through camera. What you see is not plane and static. The integration of intangible cultural heritage and AR uses mobile application of AR technology. The application can recognize contents of entity and call video packages and carry out real-time interaction with users through images shot by camera.

\section{Integration and Innovation of Landscape, Theme Park and AR Technology}

In researches on integration of landscape, theme park and $\mathrm{AR}$, we can develop quasi-holographic virtual screen, virtual surround film and demonstration projects with virtuality and 
reality combination and let computer generate holographic images to interact with entertainers and audiences; add new products such as virtual landscape and virtual decoration for living space of people; develop ground interactive projection that serves as participatory new media platform to let sightseers, visitors and researchers carry out interactive operation like in the real world; add corresponding labels or annotations for human landscape and enrich the knowledge and interestingness of tourism. For example, the mobile augmented reality system (MARS) developed by Columbia University provides additional multimedia information related to campus landscape for people to understand their history.

\section{Integration and Innovation of Intangible Cultural Heritage Games and AR Technology}

The integration of intangible cultural heritage games with culture is high level application of idea. "The integration and penetration of culture in carriers can spread spiritual connotation and values." v Turkey takes art of shadow play as APP and issues it in APP Store and vividly provides roles in 3D game of shadow puppet for players in real environment through AR technology. AR Magic System developed by interactive studio in Madrid of Spain reflects a sense of comedy through exchanging the images of users and the people around. AR technology of media convergence adds functions of video target tracking and real-time fusion. The technology helps users to lock the target in AR environment and projects objects in real environment onto the target to replace it in participating in the movement in AR environment. Meanwhile, we can adjust according to characteristics of objects in real environment. With the popularization of high definition digital camera equipment, the acquisition of video information becomes easier. People can get digital videos through DV, camera and mobile phones. At the meantime, the development of digital media application will greatly increase the demand of application of digital special effects and increasingly popularize applications with interactive processing of animation and videos.

\section{CONCLUSION}

According to the inheritance and transmission of intangible cultural heritage, the progress made by our country in policy guidance and technology driving, and the core thoughts and technical features of AR technology, more attentions are paid to the protection and inheritance of intangible cultural heritage. Countries around the world attach importance to the improvement of cultural soft power. We can carry out interaction among videos, audios, smell and touch and reality and analyze how to integrate intangible cultural heritage with AR technology to provide theoretical support for the protection and transmission of cultural resources in our country. Just as the two kinds of artistic realm including "ego-involved realm" and "super-ego realm" said by Wang Guowei, the master of Chinese culture, in the Notes and Comments on Ci Poetry, the AR technology will lead people to experience "the integration of people and objects".

\section{REFERENCES}

[1] http://www.gov.cn/zhengce/content/2014-12/03/content_9286.htm website of the People's Government of the People's Republic of China

[2] http://www.vrp3d.com/art/ official website of Vistandard Digital Technology Co., Ltd

[3] Song Lihua, Li Wanshe, Dong Tao. Digital Protection of Intangible Cultural Heritage and Construction of Knowledge Integration Platform [J], Library Journal,2015(1):73-81

[4] Bai Jiansong. Research on Digital Presentation Pattern in Museum Related to Intangible Cultural Heritage and Industrialization [J], Journal of Zhejiang Vocational Academy of Art.2011(9):112-117

[5] Yu Riji. Research on Digital Development of Intangible Cultural Heritage Based on AR Technology.[D] Wuhan University.2014. 